\title{
Análise espectro-temporal de NDVI e área da soja cultivada frente ao La Niña de 2012
}

\author{
Grazieli Rodigheri ${ }^{1}$, Denise Cybis Fontana ${ }^{1,2(*)}$, Laura Pigatto Schaparini ${ }^{2}$, Alan Pereira da Silva Falcão Mendes ${ }^{1}$ e \\ Genei Antonio Dalmago ${ }^{3}$ \\ ${ }^{1}$ Universidade Federal do Rio Grande do Sul, Programa de Pós-Graduação em Sensoriamento Remoto - PPGSR, Centro Estadual de Pesquisa em Senso- \\ riamento Remoto e Meteorologia - CEPSRM. Av. Bento Gonçalves, 9500 - Campus do Vale- Caixa Postal: 15044, CEP 91501-970 Porto Alegre, RS. E-mails: \\ grazielirodigheri@gmail.com e alanfalcaothe@gmail.com \\ ${ }^{2}$ Universidade Federal do Rio Grande do Sul - Faculdade de Agronomia. Avenida Bento Gonçalves 7712, Caixa Postal 15096, CEP 91501.970. Porto Alegre, \\ RS. E-mails: dfontana@ufrgs.bre laura_pigatto@yahoo.com.br \\ ${ }^{3}$ Embrapa Trigo. Rodovia BR 285, km 294, Caixa Postal 3081, CEP 99050-970 Passo Fundo, RS. E-mail: genei.dalmago@embrapa.br \\ ${ }^{(*)}$ Autor para correspondência.
}

\section{INFORMAÇÕES}

\section{História do artigo:}

Recebido em 14 de setembro de 2019

Aceito em 4 de março de 2020

Termos para indexação:

máscara de cultivo

sensoriamento Remoto

balanço Hídrico

\section{RESUMO}

O cultivo da soja é bastante vulnerável à estresses hídricos, podendo acarretar em prejuízos no rendimento de grãos e na produção final da cultura, principalmente quando exposto a eventos meteorológicos severos. O uso do sensoriamento remoto, através de índices de vegetação, pode propiciar análises sobre o status da cultura sob restrições hídricas. Assim, o objetivo do trabalho foi comparar os padrões espectro-temporal de NDVI e das áreas de cultivo da soja na microrregião de Passo Fundo, RS, utilizando dados MODIS, em um evento de La Niña. Foram utilizadas imagens do produto MOD13Q1, que retorna o máximo NDVI, de um ano neutro (2013/2014) e um ano de anomalia climática La Niña (2011/2012). Para as duas safras foram gerados perfis de NDVI e, então, feita uma comparação destes com variáveis meteorológicas. Os resultados mostram que o evento de La Niña foi fortemente associado a reduções no rendimento de grãos da soja, em consequência das deficiências hídricas ocorridas durante o evento. Através do perfil espectrotemporal de NDVI, nota-se que o déficit hídrico afeta o desenvolvimento da cultura.

\section{Introdução}

Estudos têm indicado uma possível conexão entre o fenômeno El Niño - Oscilação Sul (ENOS) e a variação de rendimento das culturas agrícolas produtoras de alimentos (Ferreirra, 2005), já que estes, têm impacto significativo nos climas regionais em todo o mundo, influenciando a temperatura do ar e a precipitação pluvial em muitas áreas do planeta (Peri, 2017).

No Brasil, o impacto do fenômeno ENOS provoca alterações especificamente nos padrões de precipitação pluvial de algumas regiões, afetando, em consequência, o rendimento das culturas agrícolas. De acordo com Fontana \& Berlato (1996), as alterações anuais no rendimento de 
grãos de soja no sul do Brasil são associadas às oscilações no regime pluviométrico, o qual é fortemente influenciado pela ocorrência de fenômenos climáticos de grande escala, como El Niño e La Niña. No caso do Rio Grande do Sul, o El Niño produz anomalias positivas de precipitação pluvial e a La Niña anomalias negativas, especialmente na primavera-início de verão do ano de início do fenômeno (Fontana \& Berlato, 1996). Os maiores impactos do fenômeno ENOS na precipitação pluvial ocorrem na região noroeste do Rio Grande do Sul (Fontana \& Berlato, 1997), região que possui enorme contribuição para produção de soja no Estado. Como conseqüência, a variabilidade interanual da produção agrícola no Estado está, em grande parte, associada ao ENOS (Berlato et al., 2005), pois a precipitação pluvial é a principal fonte de água para todos agroecossistemas não irrigados da região (Alberto et al, 2006).

No entanto, os padrões geográfico dos impactos da La Niña nos rendimentos de grãos da soja são diferentes daqueles causados pelo El Niño, pois as colheitas, em nível global, são muito mais afetadas, tanto positiva quanto negativamente, pelo El Niño do que pelo La Niña. Isto sugere que os impactos negativos do El Niño em alguns lugares, podem ser mitigados, até certo ponto, por seus impactos positivos em outros lugares. Já os sinais positivos e negativos de La Niña e sua compensação são mais fracos do que os do El Niño (Iizumi, 2014). Isto foi bem relatado no estudo de Iizumi et al. (2014), que analisou o efeito de ambos os eventos em cultivos de soja, milho, arroz e trigo em todo mundo. Para a América do Sul, os impactos negativos significativos da La Niña aparecem para as quatro culturas examinadas neste estudo, fazendo com que os rendimentos globais de grãos estejam abaixo do normal e as áreas impactadas negativamente respondam entre 9\% e 13\% da área colhida em todo o mundo.

Anos com ocorrência de eventos de anomalias climáticas La Niña podem ser extremamente prejudiciais ao crescimento, desenvolvimento e rendimento de grãos da soja no Rio Grande do Sul, dada a associação com a escassez hídrica para a cultura. Como exemplo disto, constata-se que um dos anos de mais baixo rendimento de grãos da soja na microrregião agrícola de Passo Fundo, no Rio Grande do Sul, foi o da safra 2011/2012, atingindo um pouco mais da metade do rendimento de grãos dos últimos anos (Figura 1) e estando exposto a um evento severo de La Niña.

Assim, a verificação de métodos que possam refletir e modelar as condições dos cultivos agrícolas e os principais agentes de alterações destes é de extrema importância, para garantir a tomada de decisões adequadas de manejo, visando minimizar os danos causados por eventos climáticos adversos. Nesse sentido, os dados oriundos de sensoriamento remoto podem ser utilizados para proporcionar melhorias na produção de informações (Mengue \& Fontana, 2015; Seo et al., 2019), com maior precisão, sobre o sta-

Figura 1. Rendimentos anuais de grãos e área cultivada de soja na microrregião agrícola de Passo Fundo - RS. A seta vermelha indica o ano sob efeito do evento da La Niña. Fonte: IBGE.

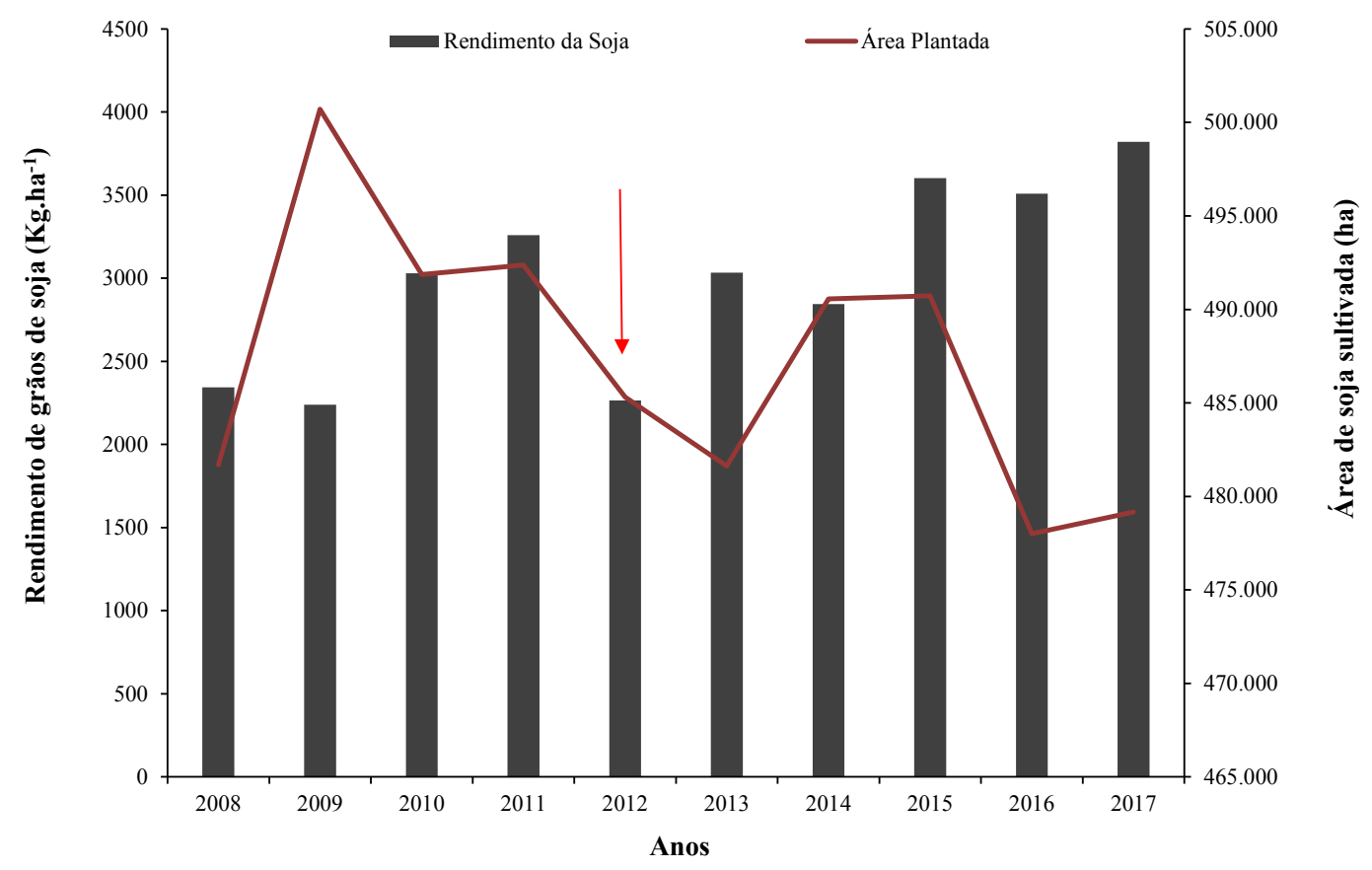


tus das culturas em grandes áreas (Berger et al., 2018). Ao contrário das observações pontuais, os sensores de satélite fornecem informações espacializadas sobre o estresse da vegetação causado pelas condições de deficiência hídrica (Zhang e Guo, 2008).

Além disso, o uso de imagens de moderada resolução espacial e alta resolução temporal para o mapeamento e monitoramento da atividade agrícola, baseado na análise do padrão espectro-temporal de índices de vegetação, pode produzir resultados com maior rapidez, precisão e ainda com menor custo operacional do que as técnicas convencionais atualmente empregadas (Mengue e Fontana, 2015). Isto porque, os índices de vegetação de banda larga, baseados em sensores ópticos tradicionais com bandas amplas de região de comprimento de onda, são os indicadores mais frequentemente usados para monitorar a dinâmica do ecossistema da vegetação devido a sua simplicidade e eficiência (Murthy et al., 2009). O Índice de Vegetação por Diferenças Normalizadas (NDVI - Normalized Difference Vegetation Index), por exemplo, é uma medida fornecida por sensores remotos, que tem uma alta correlação com o crescimento e o rendimento das culturas agrícolas (Huang e Han, 2014). Este índice é derivado da refletância na região do vermelho e do infravermelho próximo (RED NIR) e está associado à fração de radiação solar absorvida pelas plantas durante a fotossíntese (Berger et al., 2018). Assim, o NDVI está fortemente correlacionado com a ve- getação verde e pode ser utilizado como um indicador do estado, desenvolvimento e características específicas das culturas agrícolas, principalmente quando integrado a outras fontes de informação para melhorar as previsões e inferências sobre os cultivos.

O objetivo do trabalho foi comparar os padrões espectro-temporal do índice NDVI (de áreas de soja cultivadas na microrregião de Passo Fundo, RS, utilizando dados MODIS, frente a um evento de La Niña ocorrido entre julho de 2011 a maio de 2012 e um ano neutro, entre o período de julho de 2013 a maio de 2014.

\section{Material e métodos}

\section{Área de estudo}

A área de estudo foi a microrregião de Passo Fundo, localizada na região norte do estado do Rio Grande do Sul, englobando 26 municípios (Figura 2). Dentre os municípios integrantes da microrregião, aproximadamente, $60 \%$ possui como principal fonte de divisas a agropecuária (Ferretto, 2012). o clima da região é predominantemente temperado mesotérmico e bastante úmido, tipo climático Cfa - Köeppen (Alvares et al., 2013), com temperaturas do ar moderadas, estação de inverno e verão bem definidas e chuvas distribuídas ao longo do ano, apesar da alta variabilidade interanual.

Figura 2. Localização da microrregião agrícola de Passo Fundo no noroeste do Estado do Rio Grande do Sul e municípios integrantes da região, (Fonte de dados: IBGE, 1990).

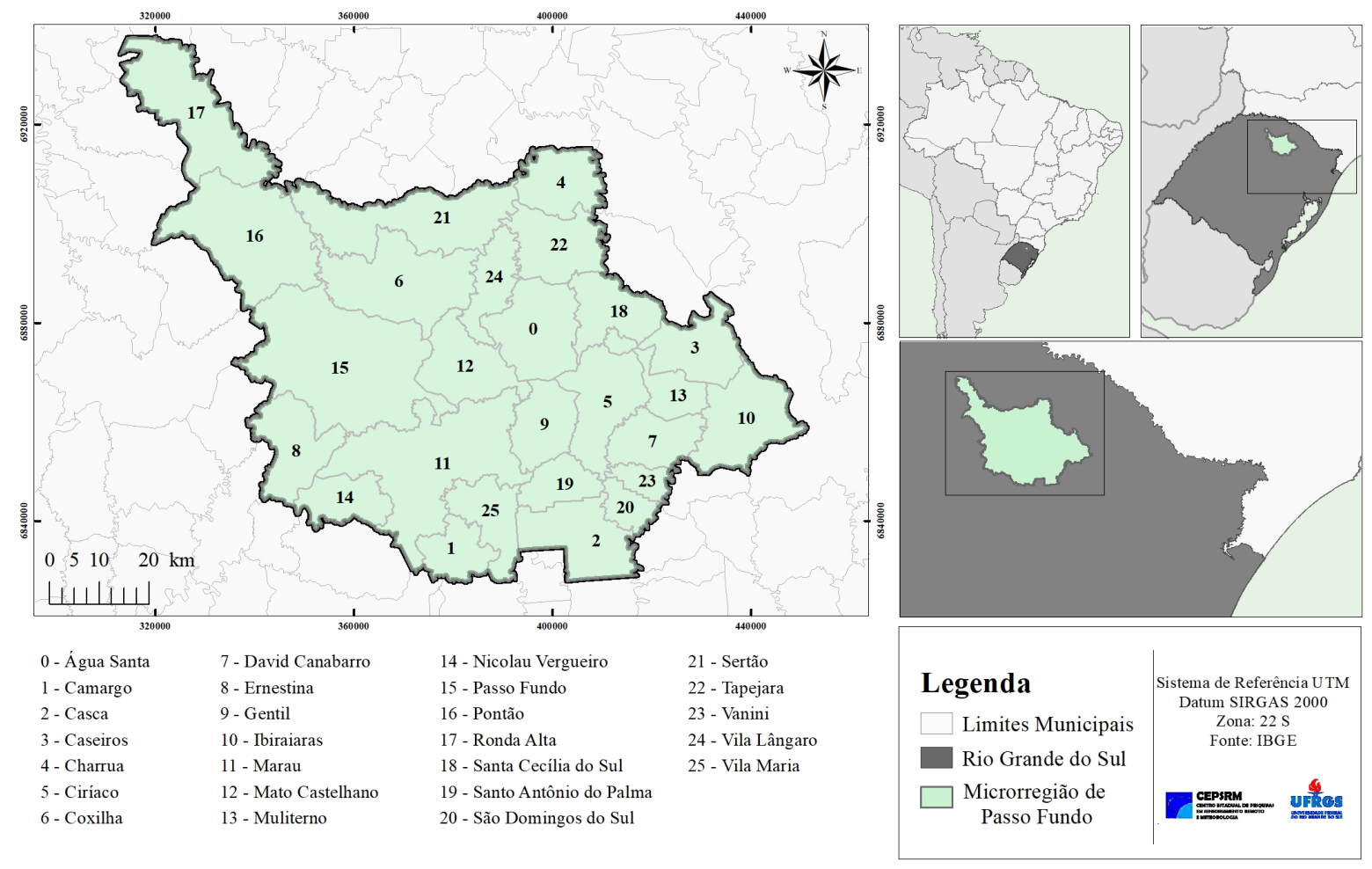




\section{Base de dados e período de estudo}

Para a realização do trabalho foram utilizadas imagens do sensor MODIS (Moderate-Resolution Imaging Spectroradiometer) a bordo da plataforma Terra, disponíveis através do portal EarthData (NASA, 2019). Foram obtidas imagens de NDVI do produto MOD13Q1, que representa uma composição de máximo valor de 16 dias consecutivos e uma resolução espacial de $250 \mathrm{~m}$. O período de estudos compreendeu um ano da La Niña, ocorrido na safra 2011/2012 e um ano neutro para comparação de dados, da safra de 2013/2014, nos meses de novembro a abril, períodos que correspondem ao ciclo da cultura da soja na região.

\section{Extração de máscaras de cultivo e perfil de NDVI}

Para avaliar a resposta de cultivos de soja frente ao evento de La Niña foi utilizado o método de extração de máscaras de cultivo, para ambos os anos de estudo. 0 método consiste na geração de imagens de mínimo e máximo NDVI referentes ao estádios iniciais e desenvolvimento pleno da cultura da soja, respectivamente, e, através destas, a geração de uma imagem diferença utilizada no cálculo das áreas de soja presentes na área de estudo.

Para a elaboração da imagem de mínimo valor de NDVI foram utilizadas três imagens dos dias julianos 273, 289 e
305 (2 imagens de novembro e 1 de dezembro), contemplando a fase de pré-semeadura e desenvolvimento inicial da cultura. As imagens dos dias julianos 17, 33 e 49 (1 imagem de janeiro e 2 de fevereiro) foram utilizadas para a geração da imagem de máximo NDVI deste período. Com as imagens diferença entre as composições de máximo e de mínimo valor foram definidas as máscaras de cultivo da soja (Figura 3), utilizando-se um limiar de corte na imagem diferença de NDVI, variando em um intervalo de 0,2 - 1, afim de indicar a presença de vegetação na área. 0 método gerou uma área de cultivo similar com os dados de área semeada com soja, disponibilizadas pelo Sistema Recuperação Automática (SIDRA) do (IBGE, 2019) (Tabela 1).

A partir da máscara de cultivo da soja, foi possível gerar o perfil de NDVI da cultura para cada ano de estudo e, assim, fazer a avaliação destes dados frente aos eventos climáticos e de anomalias.

\section{Dados Meteorológicos}

Foram utilizados dados de precipitação pluvial, temperatura do ar, insolação, umidade do ar e velocidade do vento, obtidos da estação automática e convencional do INMET (Instituto Nacional de Meteorologia), localizada na sede da Embrapa Trigo e disponível através do portal do

Figura 3. Máscaras de cultivo da soja para as safras 2012 e 2014 na microrregião agrícola de Passo Fundo - RS, representando um ano de La Niña e um ano Neutro.
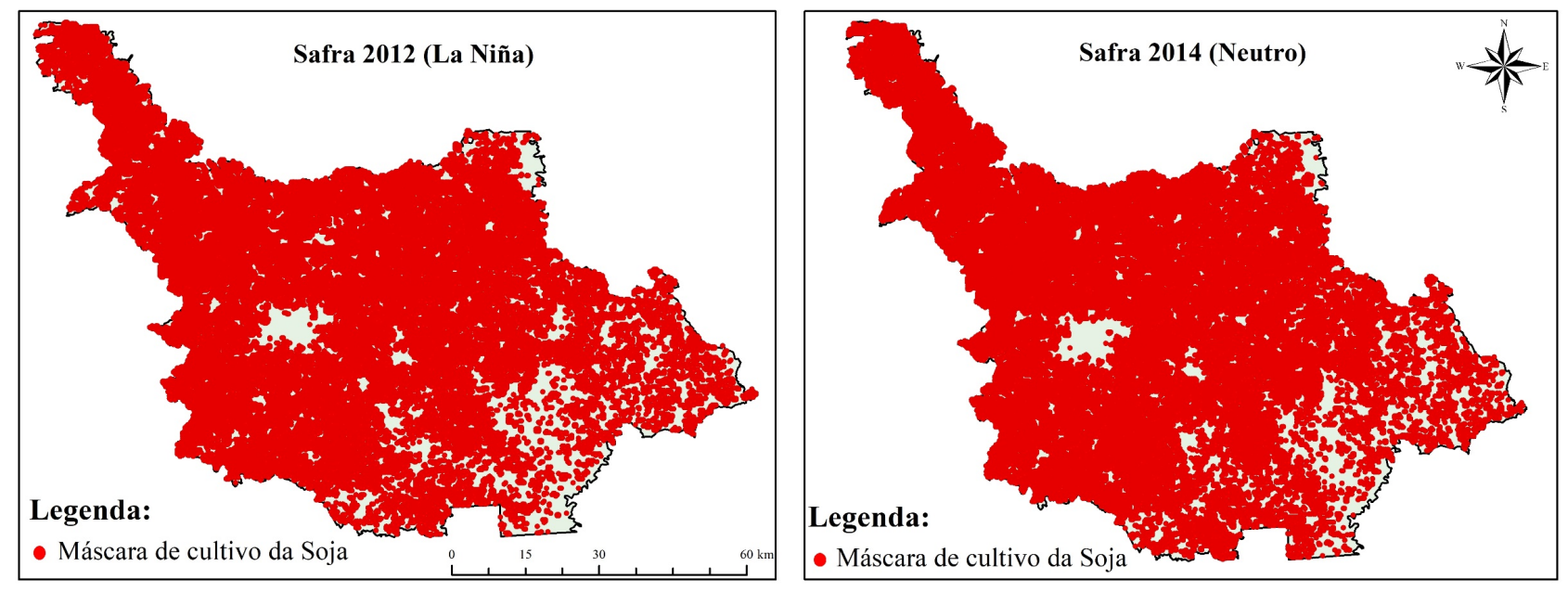

Tabela 1: Limiares de corte na imagem diferença, áreas cultivadas com soja e percentual da área ocupada com a cultura da soja na microrregião agrícola de Passo Fundo nas safras 2012 e 2014.

\begin{tabular}{ccccc} 
Safra & Limiar de corte* & Área MODIS $(\text { ha })^{* *}$ & Área IBGE (ha)*** & $\begin{array}{c}\text { Percentual de área ocupada } \\
\text { com soja na microrregião (\%) }\end{array}$ \\
\hline 2012 & $0,388-1$ & 342.475 & 342.230 & 70,52 \\
\hline 2014 & $0,465-1$ & 361.082 & 360.500 & 73,49 \\
\hline
\end{tabular}

*Valores entre 0,2 - 1, utilizados para geração das máscaras de cultivo da soja; **Área cultivada com soja, obtida através da geração da máscara de cultivo da soja sobre as imagens do produto MD013Q1; ***Área cultivada com soja obtida através do banco de dados SIDRA, (IBGE, 2019). 
Laboratório de Agrometeorologia (EMBRAPA, 2019). Os dados foram agrupados para intervalos de 16 dias (coincidindo com a resolução temporal dos dados de NDVI) das safras em estudo. A partir destes, foi calculada a evapotranspiração potencial, obtida através do método de Penman-Monteith (Allen et al., 1989) e, posteriormente, feito o cálculo do balanço hídrico meteorológico, utilizando-se método de Tornthwaite \& Matter (1955) e uma Capacidade de Água Disponível (CAD) de $75 \mathrm{~mm}$.

O método considera a precipitação pluvial como a fonte de água utilizada e o déficit hídrico climático como a diferença entre evapotranspiração potencial e a evapotranspiração real (Amorim Neto, 1989; Abatzoglou et al., 2018; Kane et al., 2015). Através do cálculo do balanço hídrico pode-se, então, obter a deficiência ou o excedente hídrico, e o total de reposição ou retirada de água no solo em cada período (Pereira, 2005).

\section{Resultados e discussão}

Houve diferença do padrão de evolução no tempo do NDVI entre as duas safras em estudo (Figura 4). Observou-se uma quantidade maior de áreas verdes durante a safra de 2013/2014, o que, possivelmente, esteja associado às condições meteorológicas favoráveis para o desenvolvi- mento da cultura neste ano. Já a safra de 2011/2012 apresentou um padrão espacial de NDVI mais esparso e com menor verdor, o que pode estar fortemente associado as restrições hídricas deste período, ocorridas em decorrência do evento de La Niña, que está associada diretamente a diminuição da precipitação pluvial nos perídos de primavera verão (Puchalski, 2000). Pode-se, portanto, inferir que o evento de La Niña possa ter comprometido o desenvolvimento da soja, visto pelo padrão espacial de NDVI e, consequentemente, ocasionado uma diminuição no rendimento de grãos da cultura neste ano.

Além disso, verificou-se uma importante mudança das áreas de soja e padrão de NDVI quando calculada a diferença entre o ano Neutro e o ano de La Niña (Figura 5). Existem regiões em que a diferença, ou seja, a mudança de um ano para o outro foi total (represetanda pelas áreas em vermelho escuro). Porém, em grande parte da região houve apenas uma diminuição do verdor da vegetação, indicado pelo menor NDVI na safra de 2012, ano de La Niña (áreas em vermelho claro e amarelo) em relação ao ano neutro. Também, ficam evidentes as áreas que se mantiveram praticamente iguais em ambas as safras, ou seja, áreas que tiveram mudanças extremamente baixas ou então, não tiveram mudança (áreas em verde).

o NDVI máximo durante a estação de cultivo da soja

Figura 4. NDVI máximo mensal dos anos de La Niña (2011-2012) e neutro (2013-2014) dos meses de novembro a abril, da microrregião de Passo Fundo-RS, nas safras de 2012 e 2014, com os respectivos valores altos (High: 1) e baixos (Low:-1) de NDVI.
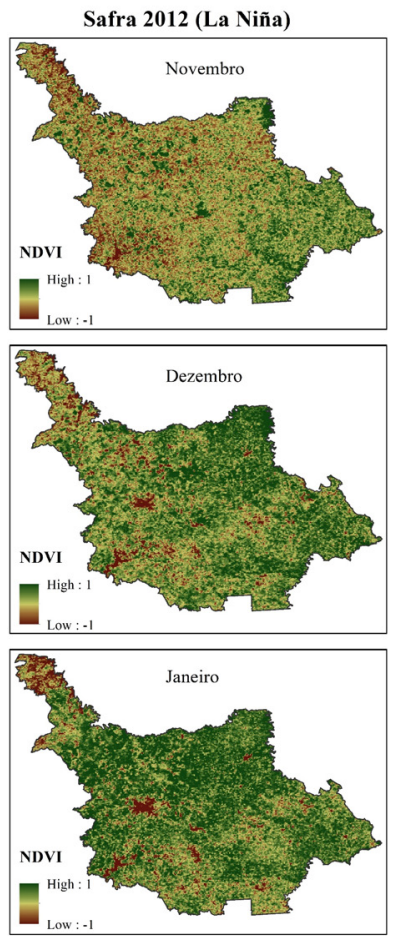
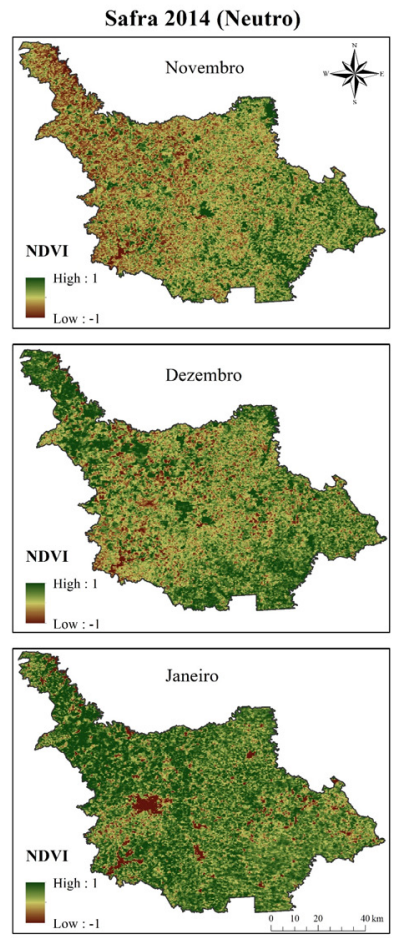
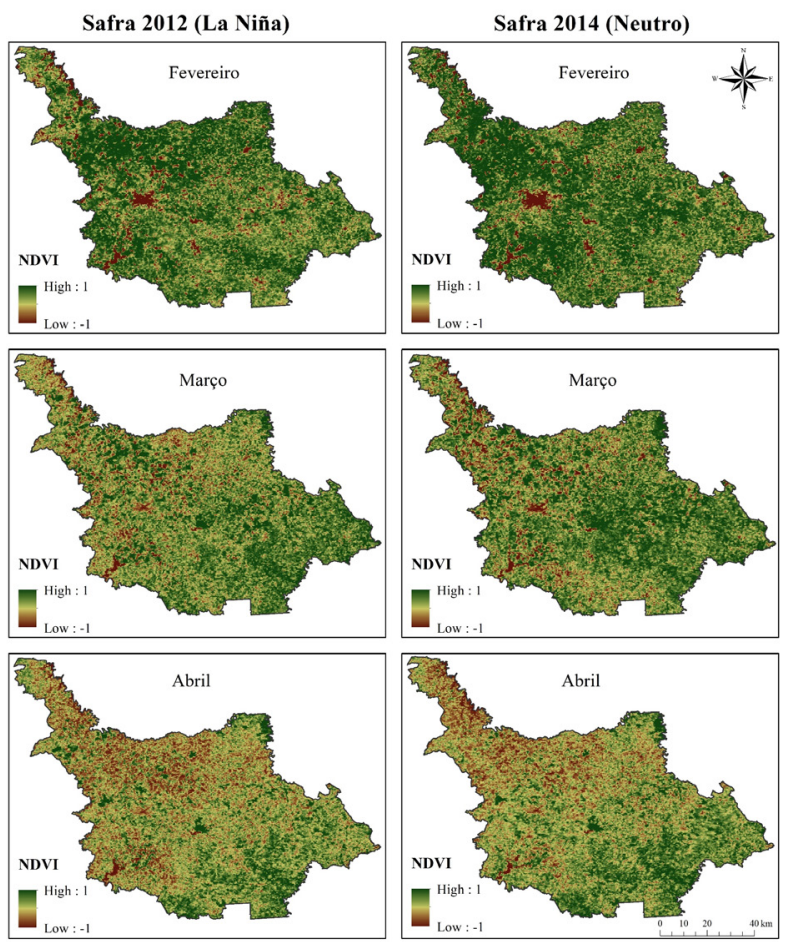
Figura 5. Imagem de Diferença de NDVI entre o ano Neutro (2014) e o ano de La Niña (2012) nos meses de dezembro, janeiro, fevereiro e março na microrregião de Passo Fundo, com as respectivas mudanças de NDVI, entre os limites altos (High: 1) e baixos (Low: 0).
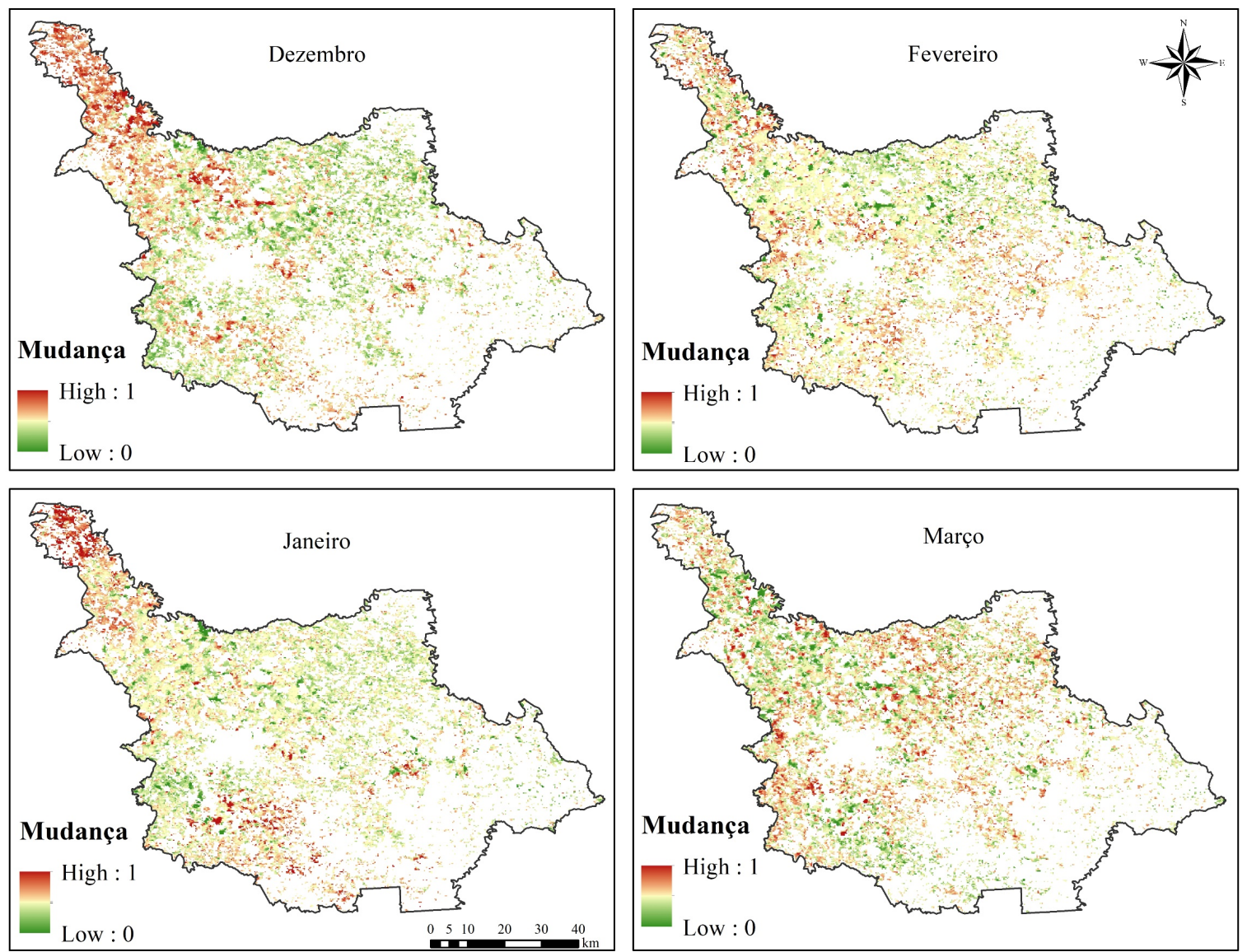

representa o pico de crescimento da vegetação, que é influenciado pelas precipitações pluviais e apoio da irrigação às culturas, entre outros (Murthy et al., 2009). Assim, durante os meses de janeiro e fevereiro os cultivos da microrregião estão em seu pico de verdor em condições normais, apresetando redução do NDVI em março associada a senescência natural da cultura. Observou-se grande diferença na forma dos perfis espectro-temporais do índice, para os dois anos de estudo (Figura 6), sendo que no ano considerado neutro houve um crescimento rápido e exponencial do NDVI, estabilizando no início de janeiro até final de fevereiro e início de março. Enquanto que, no ano de anomalia climática La Niña, o perfil de NDVI apresentou um crescimento mais lento, alcançando seu máximo entre o final de janeiro e início de fevereiro.

Murthy et al., (2009) relataram que a vegetação sob estresse possui uma reflexão mais alta na região vermelho e menor na região do infravermelho próximo do espectro, do que a vegetação saudável. A alta reflexão das culturas no infravermelho próximo está associada à geometria do dossel e à saúde das culturas, enquanto que a grande ab- sorção na região do vermelho está associada à sua biomassa e fotossíntese acumulada. Assim, há uma tendência de diminuição do valor de NDVI nos períodos em que a vegetação está sob efeito de estresse, devido a fatores internos ou externos as plantas. Portanto, um NDVI maior indica maior cobertura verde e uma diminuição no NDVI significa perda de crescimento e vigor das plantas com consequência redução na safra de grãos.

No ano neutro em análise foram observadas precipitações pluviais distribuídas ao longo do ciclo da cultura, com grandes períodos de excesso hídrico, favorecendo o crescimento vegetativo (novembro a dezembro) e reprodutivo da soja (fevereiro e março). o déficit hídrico ocorrido em janeiro parece não ter reduzido o verdor das plantas, ou então, a redução de verdor não foi grande suficiente para reduzir o valor do NDVI, dado a já conhecida limitação do NDVI em refletir mudanças de verdor quando em altos valores (saturação).

Ao contrário, para safra de 2012, sob efeito do evento La Niña, as precipitações pluviais foram abaixo da média e em geral menor do que a evapotranspiração potencial, 
Figura 6. Perfil de NDVI e Balanço Hídrico evidenciando Deficiência hídrica, Excesso Hídrico, Retirada de Água do Solo, Reposição de Água do Solo, Evapotranspiração Potencial, Evapotranspiração Real e Precipitação Pluvial para o ciclo da soja do ano La Niña (2011-2012) (a) e ano neutro (2013-2014) (b) na microrregião agrícola de Passo Fundo - RS.
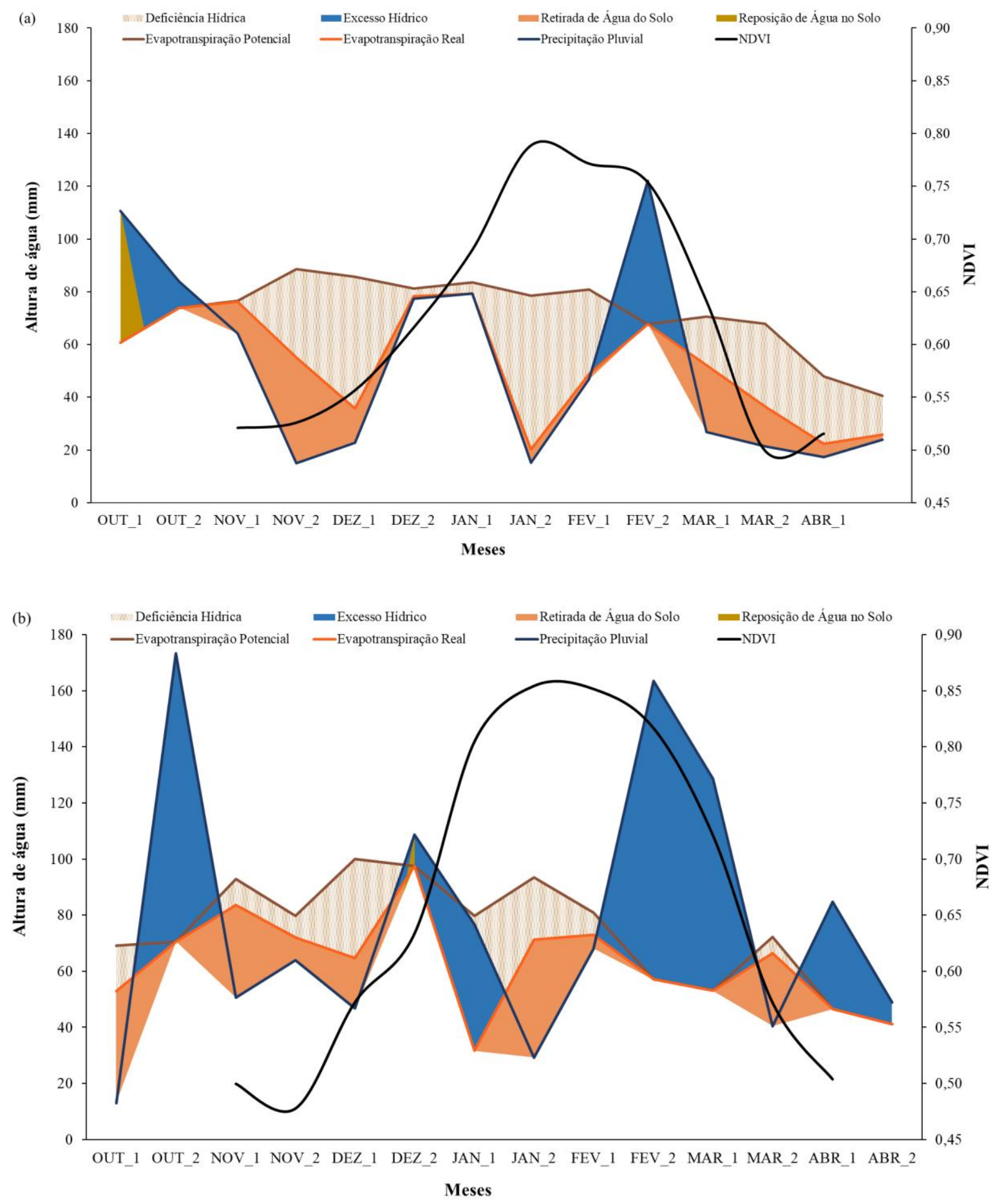

ocasionando dois grandes períodos de déficit hídrico. 0 primeiro ocorreu durante a emergência das plantas (novembro), que podem ter ocasionado, além de uma redução na população de plantas, também o atraso da emergência e, por consequência, o atraso do ciclo. Já o segundo período de déficit hídrico coincidiu com o florescimento da cultura e enchimento de grãos (janeiro), o que possivelmente foi determinante da obtenção dos menores ren- dimentos de grãos nesta safra.

Sabe-se que a disponibilidade de água no solo é importante, principalmente, nestes dois períodos críticos da soja: germinação-emergência e floração-enchimento de grãos, para assegurar uma boa uniformidade na população das plantas e um maior número e peso de grãos respectivamente (Araújo, 2010). Também é importante considerar que a medida em que as plantas se desenvolvem, a neces- 
sidade de água também aumenta, atingindo o seu máximo durante o período da floração-enchimento de grãos (7 a $8 \mathrm{~mm} / \mathrm{dia}$ ), e decrescendo após esse período (Garcia et al., 2007). Em geral, relata Araújo (2010), o consumo mais elevado de água coincide com o período em que a cultura apresenta maiores alturas e índice de área foliar, sendo que a necessidade total de água na cultura da soja, para obtenção máxima do rendimento de grãos, varia entre 450 a 800 $\mathrm{mm} /$ ciclo, dependendo das condições meteorológicas, do manejo da cultura e da duração do seu ciclo.

Assim, para que a cultura da soja se desenvolva adequadamente é necessário que a água armazenada no solo atenda o consumo hídrico da planta e, portanto, anos de anomalias climáticas relacionados a períodos secos, em geral, acarretam em prejuízos no desenvolvimento e rendimento de grãos, como ocorreu na safra de La Niña analisada. Em estudos futuros recomenda-se o ajuste de modelos de estimativa de rendimento de grãos utilizando o NDVI como indicador das etapas do ciclo.

\section{Conclusão}

O déficit hídrico afeta o desenvolvimento da cultura, o que pode ser monitorado através do perfil espectro-temporal de NDVI.

O perfil do NDVI pode ser utilizado para avaliar se os eventos de escassez hídrica ocorrem nas etapas críticas do ciclo da cultura.

\section{Agradecimento}

À Coordenação de Aperfeiçoamento de Pessoas (CAPES) pelo financiamento 001, a Universidade Federal do Rio Grande do Sul (UFRGS) e a Empresa Brasileira de Pesquisa agropecuária (Embrapa Trigo).

\section{Referências}

ABATZOGLOU, J. T.; DOBROWSKI, S. Z.; PARKS, S. A.; HEGEWISCH, K. C. Terra Climate, a high-resolution global dataset of monthly climate and climatic water balance from 1958-2015. Scientific Data, [s.l.], v. 5, n. 170191, 2018. http://dx.doi.org/10.1038/sdata.2017.191.

ALBERTO, C. M.; STRECK, N. A.; HELDWEIN, A. B.; BURIOL, G. A.; MEDEIROS, S. L. P. Água no solo e rendimento do trigo, soja e milho associados ao El Niño Oscilação Sul. Pesquisa Agropecuária Brasileira, v. 41, n. 7, p. 1067-1075, 2006. http://dx.doi.org/10.1590/S0100$204 X 2006000700001$.

ALLEN, R. G. et al. Crop evapotranspiration-Guidelines for computing crop water requirements-FAO Irrigation and drainage paper 56. Fao, Rome, v. 300, n. 9, p. D05109, 1998. http://www.fao.org/docrep/ x0490e/x0490e00.htm.

ALVARES, C. A.; STAPE, J. L.; SENTELHAS, P. C.; GONÇALVES, J. L. DE M.; SPAROVEK, G. Köppen's climate classification map for Brazil. Meteorologische Zeitschrift, [s.1.], v. 22, n. 6, p.711-728, 2013. http://dx.doi. org/10.1127/0941-2948/2013/0507.
ARAÚJO, G. K. D. Determinação e mapeamento de início do ciclo para culturas de verão no estado do Paraná por meio de imagens de satélite e dados de precipitação. 2010. Dissertação (Mestrado em Engenharia Agrícola), Universidade Estadual de Campinas, Campinas.

BERGER, A.; ETTLIN, G.; QUINCKE, C.; RODRÍGUEZ-BOCCA, P. Predicting the Normalized Difference Vegetation Index (NDVI) by training a crop growth model with historical data. Computers and Electronics in Agriculture, [s.1.], v. 161, p.305-311, 2019. https://doi.org/10.1016/j. compag.2018.04.028.

BERLATO, M. A.; FARENZENA, H.; FONTANA, D. C. Associação entre El Niño Oscilação Sul e a produtividade do milho no Estado do Rio Grande do Sul. Pesquisa Agropecuária Brasileira, [s.1.], v. 40, n. 5, p.423-432, 2005. http://dx.doi.org/10.1590/S0100-204X2005000500001.

COSTA, N. de L.; MAGALHAES, J. A.; TOWNSEND, C. R.; PAULINO, V. T. Fisiologia e manejo de plantas forrageiras. Porto Velho: Embrapa Rondonia, 2004. http://ainfo.cnptia.embrapa.br/digital/bitstream/ item/54335/1/doc85-plantasforrageiras.pdf.

EMBRAPA - Empresa Brasileira de Pesquisa Agropecuária. Embrapa Trigo, Laboratório de Agrometeorologia. 2019. Disponível em: <http://www.cnpt.embrapa.br/pesquisa/agromet/app/principal/index. php>. Acesso em: 9 set. 2019.

FERREIRA, D. B. Relações entre a variabilidade da precipitação e a produtividade agrícola de soja e milho nas regiões sul e sudeste do Brasil. 2005. 123p. Dissertação (Mestrado em Meteorologia), Instituto Nacional de Pesquisas Espaciais, São José dos Campos.

FERRETTO, Diego. Passo Fundo: estruturação urbana de uma cidade média gaúcha. 2012. Dissertação (Mestrado em Planejamento Urbano e Regional), Universidade de São Paulo, São Paulo. https:// doi:10.11606/D.16.2012.tde-17072012-143123.

FONTANA, D. C.; BERLATO, M. A. Influência do El Niño oscilação sul sobre a precipitação pluvial no Estado do Rio Grande do Sul. Revista Brasileira de Agrometeorologia, Santa Maria, v. 5, n. 1, p. 127- 132, 1997.

FONTANA, D. C.; BERLATO, M. A. Relação entre o El Niño Oscilação Sul (ENOS), precipitação e rendimento de milho no Estado do Rio Grande do Sul. Pesquisa Agropecuária Gaúcha, Porto Alegre, v.2, n.1, p. 39-45, 1996.

GARCIA, A.; PÍPOLO, A.E.; LOPES, I.A.N.; PORTUGAL, F.A.F. Instalação da lavoura de soja: Época, Cultivares, Espaçamento e População de Plantas. Londrina: Embrapa Soja, 2007. 10p. (Circular Técnica, 51). http:// ainfo.cnptia.embrapa.br/digital/bitstream/CNPSO-2009-09/27618/1/ circtec51.pdf.

HUANG, J.; HAN, D. Meta-analysis of influential factors on crop yield estimation by remote sensing. International Journal Remote Sensing. v.35, p. 2267-2295, 2014. https://doi.org/10.1080/01431161.2014.890761.

IBGE- Instituto Brasileiro de Geografia e Estatística. Divisão regional do Brasil em Mesorregiões e Microrregiões Geográficas. v.1. 1990. Disponível em: <https://biblioteca.ibge.gov.br/index.php/biblioteca-cat alogo?id=22269\&view=detalhes>. Acesso em: 05 ago. 2019.

IBGE - Instituto Brasileiro de Geografia e Estatística. Sistema IBGE de Recuperação Automática - SIDRA. 2019. Disponível em: <https://sidra. ibge.gov.br/home/pms/brasil>. Acesso em: 09 set. 2019.

IIZUMI, T.; LUO, L.; CHALLINOR, A. J.; SAKURAI, G.; YOKOZAWA, M.; SAKUMA, H.; BROWN, M. E.; YAMAGATA, T. Impacts of El Niño Southern Oscillation on the global yields of major crops. Nature Communications, v.5, n.3712, 2014. https://doi.org/10.1038/ncomms4712.

KANE, van R.; LUTZ, J. A.; CANSLER, C. A.; POVAK, N. A.; CHURCHILL, D. J.; SMITH, D. F.; KANE, J. T.; NORTH, M. P. Water balance and topography predict fire and forest structure patterns. Forest Ecology and Management, [s.1.], v. 338, p.1-13, 2015. http://dx.doi.org/10.1016/j. foreco.2014.10.038.

MENGUE, V. P.; FONTANA, D. C. Avaliação da dinâmica espectro-temporal visando o mapeamento dos principais cultivos de verão no Rio Grande do Sul. Bragantia, [s.1.], v. 74, n. 3, p.331-340, 2015. http://dx.doi. org/10.1590/1678-4499.0452. 
MURTHY, C. S.; SESHA SAI, M. V. R.; CHANDRASEKAR, K.; ROY, P. S. Spatial and temporal responses of different crop $\square$ growing environments to agricultural drought: a study in Haryana state, India using NOAA AVHRR data. International Journal of Remote Sensing, [s.l.], v. 30, n. 11, p.2897-2914, 2009. https://doi.org/10.1080/01431160802558626.

NASA - National Aeronautics and Space Administration. EarthData Search. 2019. Disponível em: < https://earthdata.nasa.gov>. Acesso em: 12 set. 2019.

AMORIM NETO, M. da S. Balanço hídrico segundo Thornthwaite \& Mather (1955). Embrapa Semiárido - Comunicado Técnico (INFOTECAE). 1989. Disponível em: <http://www.infoteca.cnptia.embrapa.br/ infoteca/handle/doc/131449>. Acesso em: 11 set. 2019.

PEREIRA, A. R. Simplificando o balanço hídrico de Thornthwaite-Mather. Bragantia, Campinas, v.64, n.2, p.311-313, 2005.

PERI, M. Climate variability and the volatility of global maize and soybean prices. Food Security, [s.1.], v. 9, n. 4, p.673-683, 2017. https://doi. org/10.1007/s12571-017-0702-2.
PUCHALSKI, L. A. Efeitos associados ao El Niño e La Niña na temperatura média, precipitação pluvial e no déficit hídrico no Estado do Rio Grande do Sul. 2000. 100p. Dissertação (Mestrado em Fitotecnia), Universidade Federal do Rio Grande do Sul, Porto Alegre.

SEO, B.; LEE, J.; LEE, K.D.; HONG, S.; KANG, S. Improving remotely-sensed crop monitoring by NDVI-based crop phenology estimators for corn and soybeans in Iowa and Illinois, USA. Field Crops Research, v.238, p.113-128, 2019. https://doi.org/10.1016/j.fcr.2019.03.015.

THORNTHWAITE, C.W.; MATHER, J.R. The water balance. Publications in climatology. Laboratory of Climatology, New Gersey, v.8, 104 p. 1955.

ZHANG, C.; GUO, X. Monitoring Northern Mixed Prairie Health Using Broadband Satellite Imagery. International Journal of Remote Sensing, v.29, p.2257-2271, 2008. https://doi. org/10.1080/01431160701408378.

REFERENCIAÇÃO

RODIGHERI, G.; FONTANA, D. C.; SCHAPARINI, L. P.; MENDES, A. P. S. F. DALMAGO, G. A. Análise espectro-temporal DE NDVI e área da soja cultivada frente ao La Niña de 2012. Agrometeoros, Passo Fundo, v.27, n.1, p.63-72, set 2019.

Declaração: os trabalhos estão sendo publicados nesse número de AGROMETEOROS (v.27, n.1, set 2019) conforme foram aceitos pelo XXI Congresso Brasileiro de Agrometeorologia, realizado de 12 a 16 de agosto de 2019, em Catalão, Goiás, sem revisão editorial adicional da revista. 


\title{
Spectral-temporal analysis of NDVi and cultivated soybean area in front of La Niña 2012
}

\author{
Grazieli Rodigheri ${ }^{1}$, Denise Cybis Fontana ${ }^{1,2(*)}$, Laura Pigatto Schaparini' ${ }^{2}$, Alan Pereira da Silva Falcão Mendes ${ }^{1}$ and \\ Genei Antonio Dalmago ${ }^{3}$
}

${ }^{1}$ Universidade Federal do Rio Grande do Sul, Programa de Pós-Graduação em Sensoriamento Remoto - PPGSR, Centro Estadual de Pesquisa em Sensoriamento Remoto e Meteorologia - CEPSRM. Av. Bento Gonçalves, 9500 - Campus do Vale- Caixa Postal: 15044, CEP $91501-970$ Porto Alegre, RS, Brazil. E-mails: grazielirodigheri@gmail.com and alanfalcaothe@gmail.com

${ }^{2}$ Universidade Federal do Rio Grande do Sul - Faculdade de Agronomia. Avenida Bento Gonçalves 7712, Caixa Postal 15096, CEP 91501.970. Porto Alegre, RS, Brazil. E-mails: dfontana@ufrgs.br and laura_pigatto@yahoo.com.br

${ }^{3}$ Embrapa Trigo. Rodovia BR 285, km 294, Caixa Postal 3081, CEP 99050-970 Passo Fundo, RS, Brazil. E-mail: genei.dalmago@embrapa.br

${ }^{(*)}$ Corresponding author.

\section{ARTICLE INFO}

\section{Article history:}

Received 14 September 2019

Accepted 4 March 2020

\section{Index terms:}

crop mask

remote Sensing

water balance
ABSTRACT

Soybean cultivation is very vulnerable to water stresses, which can lead to losses in final crop production, especially when exposed to severe weather events. The use of remote sensing through vegetation indices can provide analyzes on crop status under water restrictions. Thus, the objective of this work was to compare the NDVI spectral-temporal patterns and soybean crop areas in the Passo Fundo, RS, Brazil micro-region using MODIS data during a La Niña event. Were used images of the product MOD13Q1, which returns the maximum NDVI, of a neutral year (2013/2014) and a year of climatic anomaly La Niña (2011/2012). For the two harvests NDVI profiles were generated and then a comparison of these with meteorological variables was done. The results show that the La Niña event was strongly associated with reductions in grain yield of soybean, as a consequence of the water deficiencies occurred during the event. Through the spectral-temporal profile of NDVI, it is noticed that the water deficit affects the development of the culture.

\section{CITATION \\ RODIGHERI, G.; FONTANA, D. C.; SCHAPARINI, L. P.; MENDES, A. P. S. F. DALMAGO, G. A. Análise espectro-temporal DE NDVI e área da soja cultivada frente ao La Niña de 2012. Agrometeoros, Passo Fundo, v.27, n.1, p.63-72, set 2019.}

Disclaimer: papers are published in this issue of AGROMETEOROS (v. 27, n.1, set 2019) as accepted by the XXI Congresso Brasileiro de Agrometeorologia, held August 12-16, 2019 in Catalão, Goiás State , Brazil, without further revision by editorial board. 